\title{
Intravenous infusion of human umbilical cord Wharton's jelly-derived mesenchymal stem cells as a potential treatment for patients with COVID-19 pneumonia
}

Yingxin Zhang ${ }^{1+}$, Jie Ding ${ }^{1+}$, Shaoda Ren ${ }^{1}$, Weihua Wang ${ }^{1}$, Yapei Yang ${ }^{1}$, Shuangjing Li ${ }^{1}$, Min Meng ${ }^{1}$, Tiejun Wu ${ }^{2}$,

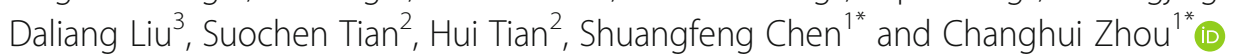

\begin{abstract}
The novel coronavirus disease 2019 (COVID-19) has grown to be a global public health emergency since patients were first detected in Wuhan, China. Thus far, no specific drugs or vaccines are available to cure the patients with COVID-19 infection. The immune system and inflammation are proposed to play a central role in COVID-19 pathogenesis. Mesenchymal stem cells (MSCs) have been shown to possess a comprehensive powerful immunomodulatory function. Intravenous infusion of MSCs has shown promising results in COVID-19 treatment. Here, we report a case of a severe COVID-19 patient treated with human umbilical cord Wharton's jelly-derived MSCs (hWJCs) from a healthy donor in Liaocheng People's Hospital, China, from February 24, 2020. The pulmonary function and symptoms of the patient with COVID-19 pneumonia was significantly improved in 2 days after hWJC transplantation, and recovered and discharged in 7 days after treatment. After treatment, the percentage and counts of lymphocyte subsets $\left(\mathrm{CD}^{+}, \mathrm{CD}^{+}\right.$, and $\mathrm{CD}^{+} \mathrm{T}$ cell) were increased, and the level of IL-6, TNF-a, and C-reactive protein is significantly decreased after hWJC treatment. Thus, the intravenous transplantation of hWJCs was safe and effective for the treatment of patients with COVID-19 pneumonia, especially for the patients in a critically severe condition. This report highlights the potential of hWJC infusions as an effective treatment for COVID-19 pneumonia.
\end{abstract}

Keywords: COVID-19, Human umbilical cord Wharton's jelly-derived MSCs, Immunomodulatory, Treatment

\section{Introduction}

The novel coronavirus disease 2019 (COVID-19) has grown to be a global public health emergency since patients were first detected in Wuhan, China, in December 2019 [1, 2]. The 2019 novel coronavirus had infected 418,209 people worldwide (among which 18,724 were killed) as of 25 March, 2020. Including the ground-glass opacity in the lung, the other typical diagnosis characteristic of critically

\footnotetext{
*Correspondence: csfcscn@163.com; zhouchanghui008@163.com

${ }^{+}$Yingxin Zhang and Jie Ding contributed equally to this work.

'Department of Central Laboratory, Liaocheng People's Hospital, Dongchang West Road, No.67, Liaocheng 252000, Shandong Province, China Full list of author information is available at the end of the article
}

ill patients was a significant decrease in lymphocytes along with the increase of neutrophils [2-5]. Currently, no specific drugs or vaccines are available to cure patients with COVID-19 infection $[2,6]$. Therefore, novel strategies for critically ill COVID-19 are urgently needed. Critically ill patients have higher concentrations of interleukin-6 (IL-6), granulocyte colony-stimulating factor (G-CSF), and tumor necrosis factor- $\alpha$ (TNF- $\alpha$ ), indicating the virus can stimulate a terrible cytokine storm in the lung, which may cause severe organ injury and death [5-8]. Therefore, avoiding the cytokine storm may be the key for the treatment of COVID-19-infected patients [6, 9].

(c) The Author(s). 2020 Open Access This article is licensed under a Creative Commons Attribution 4.0 International License, which permits use, sharing, adaptation, distribution and reproduction in any medium or format, as long as you give appropriate credit to the original author(s) and the source, provide a link to the Creative Commons licence, and indicate if changes were made. The images or other third party material in this article are included in the article's Creative Commons licence, unless indicated otherwise in a credit line to the material. If material is not included in the article's Creative Commons licence and your intended use is not permitted by statutory regulation or exceeds the permitted use, you will need to obtain permission directly from the copyright holder. To view a copy of this licence, visit http://creativecommons.org/licenses/by/4.0/ The Creative Commons Public Domain Dedication waiver (http://creativecommons.org/publicdomain/zero/1.0/) applies to the data made available in this article, unless otherwise stated in a credit line to the data. 
Mesenchymal stem cells (MSCs) have been widely used to treat autoimmune disease, graft-versus-host disease (GVHD), and other diseases with very good safety [10, 11]. MSCs play a positive role in immunomodulatory effects via secreting many types of cytokines by paracrine secretion or make direct interactions with immune cells $[3,11]$. Among which, the human umbilical cord Wharton's jelly-derived MSCs (hWJCs) can be easily obtained and cultured. hWJCs have shown very significant immunomodulation and tissue repair effects with low immunogenicity, which makes them a very ideal candidate for allogeneic adoptive transfer therapy $[3,11]$. Owing to their powerful immunomodulatory ability, hWJC transplantation may have beneficial effects on preventing or attenuating the cytokine storm $[6,9,12,13]$.

Up to now, the therapeutic effects of hWJCs on COVID-19 is still rarely reported. Here, we will introduce a critically ill elder male patient in China infected with COVID-19. The clinical outcome of hWJC adoptive transfer therapy will be discussed to explore their therapeutic potential for COVID-19-infected patients.

\section{Patient and methods}

The study was conducted in Liaocheng People's Hospital, China, and approved by the ethics committee of the hospital (2020003, Supplementary Figure 1). This patient without malignant tumors and have not participated in other clinical trials within 3 months.

\section{Case presentation}

On February 7, 2020, a 54-year-old man presented to Yanggu People's Hospital, Shandong, with a 4-day history of cough, chest tightness, and fever. Apart from a 2-year history of diabetes, the patient had no other specific medical history. The physical examination showed a body temperature of $38.0^{\circ} \mathrm{C}$, blood pressure of $141 / 87 \mathrm{mmHg}$, and pulse of 81 beats per minute. A blood routine examination was arranged urgently, and throat swabs were collected. The result revealed that the white cell count and absolute lymphocyte count were $7.59 \times 10^{9} / \mathrm{L}$ (reference range $3.5 \sim 9.5 \times 10^{9} / \mathrm{L}$ ) and $0.24 \times 10^{9} / \mathrm{L}$ (reference range $1.1 \sim 3.2 \times 10^{9} / \mathrm{L}$ ), respectively; C-reactive protein (CRP), $59.64 \mathrm{mg} / \mathrm{L}$ (reference range $0 \sim 10 \mathrm{mg} / \mathrm{L}$ ); influenza A and $\mathrm{B}$ virus antigen (-); and routine anti-inflammation and antivirus therapy were given for supportive treatment.

On February 9, 2020, the real-time polymerase chain reaction (RT-PCR) assay confirmed that the patient's specimen tested positive for COVID-19. Then, the patient was admitted to an airborne isolation unit in Liaocheng Infectious Disease Hospital for clinical observation.

On February 11, 2020, the patient felt severe shortness of breath, and the oxygen saturation values decreased to as low as $87.9 \%$. Related laboratory results showed $\mathrm{PH}$ (7.46), $\mathrm{PCO}_{2}$ (26 mmHg), $\mathrm{PO}_{2}(50 \mathrm{mmHg}), \mathrm{HCO}_{3}$ (18.4 $\mathrm{mmol} / \mathrm{L}$ ). The doctors decided to change the diagnosis to COVID-19 (critically severe type), and the patient was admitted to the ICU of Liaocheng People's Hospital for better treatment.

On February 12, 2020, the shortness of breath even got worse under the oxygen supplementation. The doctor speeded up the oxygen airflow to $45 \mathrm{~L}$ per minute. Chest computerized tomography (CT) clearly showed evidence of pneumonia and ground-glass opacity, in the right and left lungs (Fig. 1A-1-A-4). According to the guideline for the diagnosis and treatment of COVID-19 [14], the patient was treated with antiviral therapy of lopinavir/ritonavir, IFN- $\alpha$ inhalation, and also intravenous injection of levofloxacin, tanreqing capsule, xuebijing, thymosin $\alpha 1$, methylprednisolone, and immunoglobulin. During this time, the patient received antipyretic therapy. More treatments were conducted consisting of electrocardiograph monitoring, potassium chloride sustained-release tablets (oral, $1 \mathrm{~g}$ per time, 2 times per day), plasma exchange and regulated intestinal microflora of patient, etc. Finally, the discomfort was released, and the oxygen saturation increased to $98 \%$.

On February 13 to 21, the patient's vital physical signs remained largely stable, apart from the development of intermittent fevers and shortness of breath.

On February 22, the patient took a turn for the worse (Fig. 1B-1-B-4). Considering the severe organ injury caused by an inflammatory response, hWJC adoptive transfer therapy was proposed under the advice and guidance of the specialist group. The family member and patient agreed to try hWJC adoptive transfer therapy. The therapeutic scheme was then discussed and approved by the ethics committee of the hospital, and consent forms were signed by the family member before the therapy. On February 24, the patient receives hWJC transfusion.

On March 1, the patient felt much better. The shortness of breath was significantly recovering. The CRP decreased to $27.2 \mathrm{~g} / \mathrm{L}$, the absolute lymphocyte count rose to $0.66 \times 10^{9} / \mathrm{L}$, and the inflammatory factors reduced to normal levels, which indicated that the patient was recovering rapidly. On March 2, the patient meets the discharge standard, and the medical observation is canceled

\section{hWJC preparation}

The clinical-grade hWJCs were supplied by the Central Laboratory of Liaocheng People's Hospital. The cell product has been certified by the National Institutes for Food and Drug Control of China (authorization number: SH201900594 and SH201900597).

hWJCs were expanded as previously described [11]. Briefly, following the standard operating procedures, human umbilical cords were obtained under sterile conditions from full-term infants delivered by cesarean section; residual blood was fully washed by phosphate-buffered 


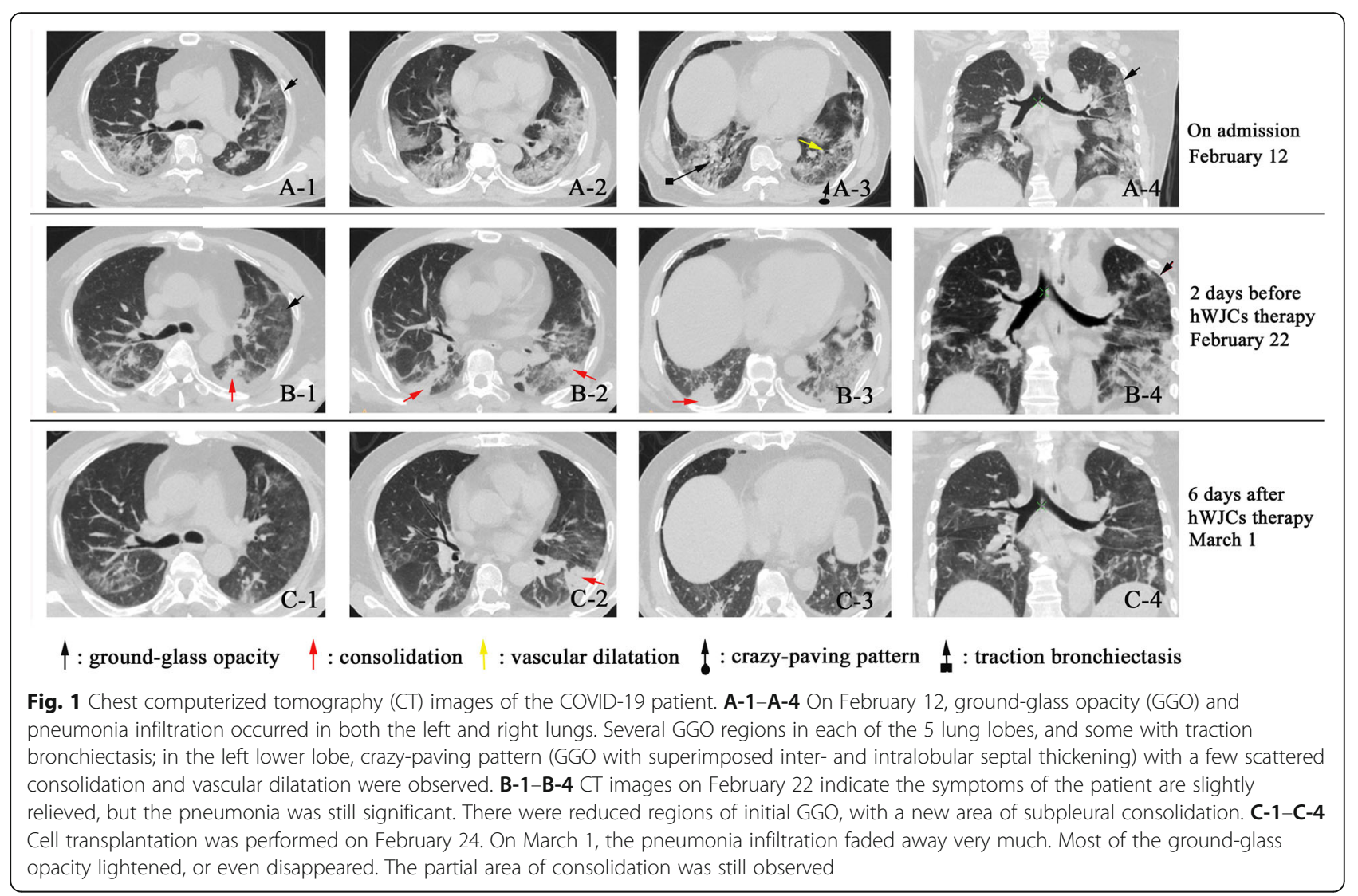

saline. The umbilical cord membrane was stripped, and the umbilical cord blood vessels (two arteries and one vein) were removed to retain the Wharton's jelly. The Wharton's jelly was cut into $1-\mathrm{mm}^{3}$ pieces and then cultured in DMEM/F12 (GIBCO, USA) supplemented with 10\% fetal bovine serum (FBS) (GIBCO, USA). The culture was maintained at $37^{\circ} \mathrm{C}$ with saturated humidity and $5 \%(\mathrm{v} / \mathrm{v}) \mathrm{CO}_{2}$. The medium was changed every 3 days. hWJCs were passaged at $80 \%$ confluence treatment with $0.25 \%$ trypsin (Sigma, USA) and 0.02\% EDTA (Sigma, USA).

\section{hWJC characterization and transplantation}

hWJCs were characterized by flow cytometric analysis of hWJC-associated cell surface markers, as previously described [11]. hWJC-associated cell surface marker analysis was performed by incubating 200,000 hWJCs with a combination of antibodies: CD90-fluorescein isothiocyanate (FITC, 555595), CD73-phycoerythrin (PE, 550257), CD105-phycoerythrin (PE, 560839), CD45(APC, 555485), and CD34-phycoerythrin-Cy (PE-Cy, 5555823). All were manufactured by Becton-Dickinson BD, San Diego, CA, and hWJCs were analyzed using a FACS Canto cytometer (BD Biosciences, San Jose, CA) and the Diva Software (BD Biosciences, San Jose, CA).

Release testing before administration comprised morphology (fibroblast-like adherent cells), viability (>90\% live cells measured by trypan blue assay), purity by FACS ( $\geq$ 95\% $\mathrm{CD}^{+} 0^{+}, \mathrm{CD}^{+} 3^{+}, \mathrm{CD}_{105^{+}}, \mathrm{CD} 34^{-}$, and $\mathrm{CD} 45^{-}$cells), endotoxin and mycoplasma and sterility testing (-), and cell viability test ( $>90 \%)$.

The hWJCs injected to the patient were from fresh culture. Patients received dexamethasone $2 \mathrm{mg}$ before intravenous infusion of hWJCs. hWJCs were suspended in 100 $\mathrm{mL}$ of normal saline, and the total number of transplanted cells was calculated by $1 \times 10^{6}$ cells per kilogram of weight. The injection was performed about 40 min with a speed of 40 drops per minute. During hWJC injection, other conventional therapies are used as usual.

The patient was assessed by the investigators after receiving the investigational product. The clinical, laboratory, and radiological outcomes were recorded and certified by a trained group of doctors. The detailed record included primary safety data (infusional and allergic reactions, secondary infection, and life-threatening adverse events) and the efficacy outcomes mainly included the level of the cytokine variation, the level of CRP in the plasma, the lymphocyte subpopulations, the chest $\mathrm{CT}$, and the patient symptoms.

\section{COVID-19 nucleic acid detection}

RT-PCR analysis of COVID-19 nucleic acid was performed before and after hWJC transplantation, as previously described [15]. Briefly, viral RNA was extracted 
from $200 \mu \mathrm{L}$ of respiratory specimens from patients suspected of having COVID-19 infection using the Nucleic Acid Extraction Kit (TianLong, Suzhou, China) according to the manufacturer's recommended procedure. RT-PCR assay was performed using a COVID-19 nucleic acid detection kit according to the manufacturer's protocol (Shanghai BioGerm Medical Technology Co Ltd., national medical device registration approval number: 20203400065). It was performed under the following conditions: incubation at $50^{\circ} \mathrm{C}$ for $10 \mathrm{~min}$ and $95^{\circ} \mathrm{C}$ for $5 \mathrm{~min}, 40$ cycles of denaturation at $95^{\circ} \mathrm{C}$ for 10 $\mathrm{s}$, and extending and collecting fluorescence signal at $55^{\circ} \mathrm{C}$ for $40 \mathrm{~s}$. A cycle threshold value (Ct value) less than 38 was defined as a positive test result, and a $\mathrm{Ct}$ value of 40 or more was defined as a negative test.

\section{Results}

\section{Safety outcome}

Before the hWJC transplantation, the patients had symptoms of high fever $\left(38.5^{\circ} \mathrm{C} \pm 0.5^{\circ} \mathrm{C}\right)$, weakness, shortness of breath, and low oxygen saturation. However, 2 7 days after transplantation, all the symptoms disappeared, and the oxygen saturations rose to $98 \%$ at rest. In addition, no acute infusion-related or allergic reactions were observed within $2 \mathrm{~h}$ after transplantation. Similarly, no delayed hypersensitivity or secondary infections were detected after treatment.

\section{The efficacy outcome}

Both fever and shortness of breath disappeared on the 2nd day after hWJC transplantation. Chest CT imaging showed that the ground-glass opacity and pneumonia infiltration had largely reduced on the 6th day after hWJC transplantation (Fig. 1C-1-C-4). The CT score of the pulmonary involvement [16] was represented in Table 1.

The immunoregulatory function of hWJCs contributed to the main efficacy outcome. As shown in Fig. 2, the percentage and counts of $\mathrm{CD}^{+} \mathrm{T}$ cell, $\mathrm{CD}^{+} \mathrm{T}$ cell, and $\mathrm{CD}^{+} \mathrm{T}$ cell were increased, which indicated that the immune function of patients was improved after the hWJC administration. Meanwhile, the levels of plasma CRP and inflammatory factors (IL-6 and TNF- $\alpha$ ) were all decreased after hWJC treatment
(Fig. 3). All these results indicated that the inflammation status of the patient was alleviating quickly.

For the critically severe patient, before hWJC transplantation, COVID-19 nucleic acid was positive. Six days after transplantation (March 1), COVID-19 nucleic acid turned to be negative.

\section{Discussion}

The cure of COVID-19 is essentially dependent on the patient's own immune system. The virus infection caused a total function failure of the lymphocytes, even of the whole immune system $[6,17]$. However, when the overactivated immune system kills the virus, it produces a large amount of inflammatory factors, leading to severe cytokine storms $[6,15]$. The cytokine storms deteriorated the patient's states which may cause the disabled function of endothelial cells and the capillary leakage and could lead to multiple organ failure $[3,6]$.

MSC therapy can inhibit the overactivation of the immune system and promote endogenous repair by improving the microenvironment [6]. After entering the human body through intravenous infusion, part of the MSCs accumulates in the lung, which could improve the pulmonary microenvironment, protect alveolar epithelial cells, prevent pulmonary fibrosis, and improve lung function [12, 13]. Meanwhile, recent studies suggest that MSCs played the vital immune modulation roles on lymphocyte subsets and can secrete anti-inflammatory factors to prevent the cytokine storm $[6,9,11]$.

Our results showed that the administration of intravenous injection of hWJCs significantly improved the inflammation and immune situation in severe COVID-19 patients. After hWJC adoptive transfer, no obvious side effects were observed, indicating it was well tolerated. The serum CRP and inflammatory factors (IL- 6 and TNF- $\alpha$ ) of the patient were gradually reduced, and some other vital signs were also improved. The trachea cannula was also pulled off, and the patient could ambulate on the ground from February 26 as well. Meanwhile, the counts of $\mathrm{CD}^{+}$, $\mathrm{CD}^{+}$, and $\mathrm{CD} 8^{+} \mathrm{T}$ cell were remarkably increased after intravenous injection of hWJCs. All these results suggested that transplantation of hWJCs could improve the outcome of COVID-19 patients maybe through regulating

Table 1 The CT score of the pulmonary involvement

\begin{tabular}{llllll}
\hline Date & Position of the lung, score & & & \\
\hline February 12 & Left upper lobe, 2 & Left lower lobe, 3 & Right upper lobe, 1 & Right middle lobe, 1 & Right lower lobe, 3 \\
February 22 & Left upper lobe, 3 & Left lower lobe, 4 & Right upper lobe, 1 & Right middle lobe, 1 & Right lower lobe, 3 \\
March 1 & Left upper lobe, 1 & Left lower lobe, 2 & Right upper lobe, 1 & Right middle lobe, 1 & Right lower lobe, 2 \\
\hline
\end{tabular}

A semi-quantitative scoring system was used to quantitatively estimate the pulmonary involvement of all abnormalities on the basis of the area involved [16]. Each of the 5 lung lobes was visually scored from 0 to 5 as follows: 0 , no involvement; $1,<5 \%$ involvement; $2,25 \%$ involvement; $3,26-49 \%$ involvement; $4,50-$ $75 \%$ involvement; and 5, > 75\% involvement 


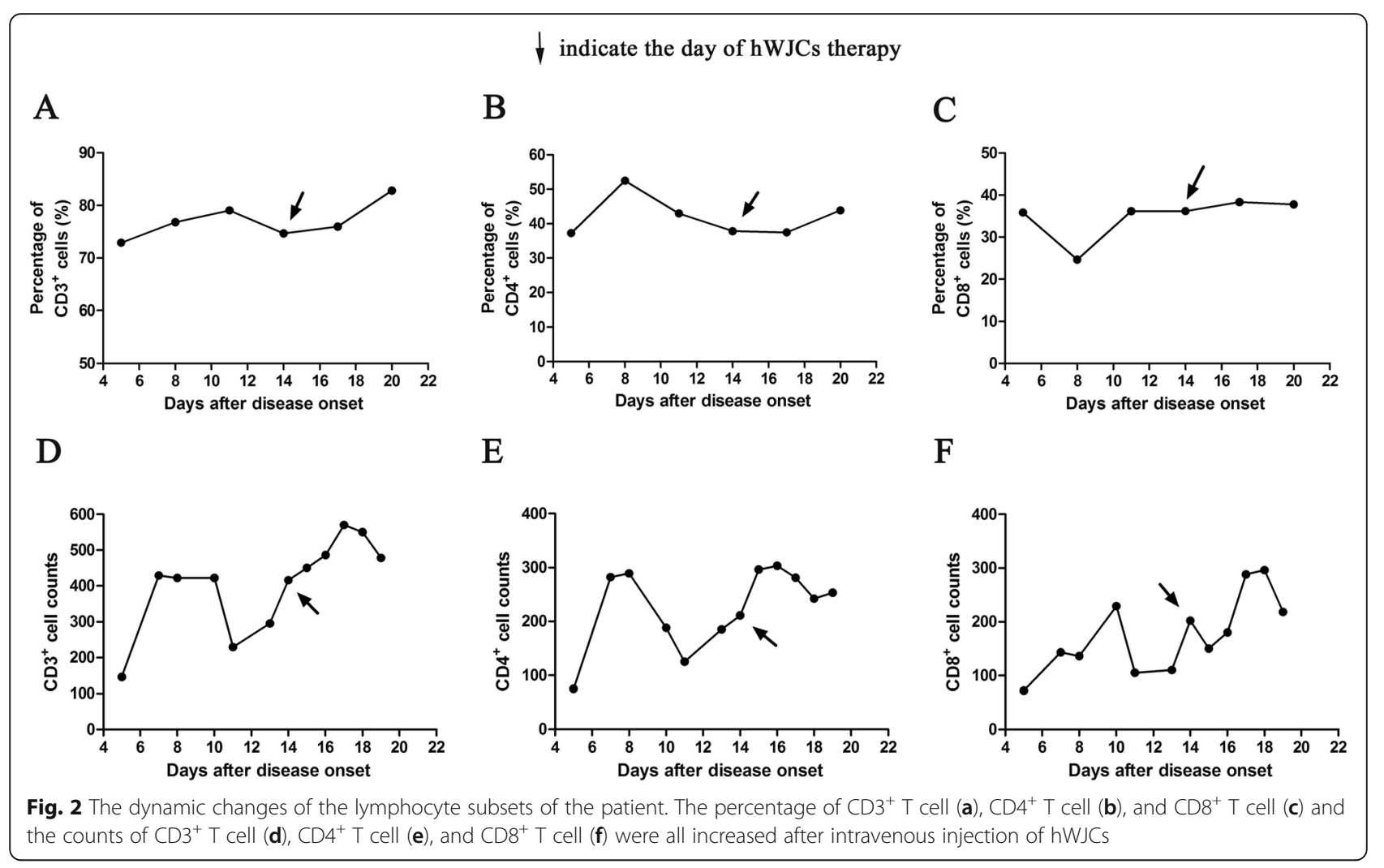

inflammatory response and promoting the recovery of antiviral immune cells and organs.

In addition, emerging evidences indicate that the epithelial and endothelial regulated cell death (RCD) caused by inflammation is closely related to the pathogenesis of many pulmonary disorders [18]. MSCs are known to improve cell survival and prevent apoptosis, necroptosis, and pyroptosis occurring in various parenchymal or nonparenchymal cells and immune cells under unfavorable conditions $[18,19]$. The assessment of the ability of hWJCs in modulating RCD would certainly benefit patients receiving hWJC therapy, particularly those with
COVID-19. Therefore, how hWJCs can counteract cell death and promote cell regeneration should be discussed in the future.

\section{Conclusions}

As a conclusion, we proposed that the adoptive transfer therapy of hWJCs might be an ideal choice to be used for COVID-19 treatment. Although only one case was shown here, it would also be very important to inspire more similar clinical practice to treat such critically ill COVID-19 patients.

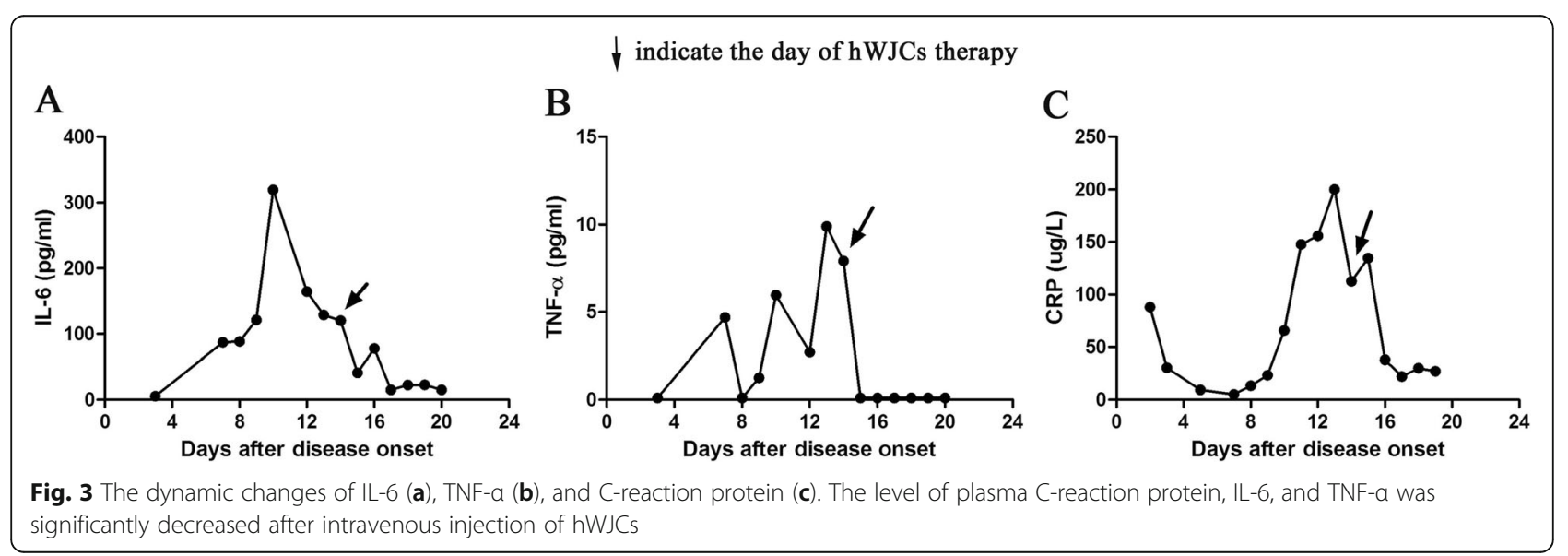




\section{Supplementary information}

Supplementary information accompanies this paper at https://doi.org/10. 1186/s13287-020-01725-4.

Additional file 1: Supplementary Figure 1. Ethical approval of hWJCs for the treatment of patients with COVID-19 pneumonia.

\section{Abbreviations}

COVID-19: Novel coronavirus disease 2019; IL-6: Interleukin-6; G-

CSF: Granulocyte colony-stimulating factor; TNF-a: Tumor necrosis factor-a; MSCs: Mesenchymal stem cells; hWJCs: Human umbilical cord Wharton's jelly-derived mesenchymal stem cells; GVHD: Graft-versus-host disease; CRP: C-reactive protein; RT-PCR: Real-time polymerase chain reaction; $\mathrm{CT}$ : Computerized tomography; GGO: Ground-glass opacity; FBS: Fetal bovine serum; RCD: Regulated cell death

\section{Authors' contributions}

$\mathrm{CHZ}, \mathrm{YXZ}$, and JD contributed to data analysis and interpretation, data collection, literature review, and drafted the manuscript. CHZ and SFC contributed to the conception and design of the study. SDR, YXZ, and JD contributed to the MSC production and characterization. $\mathrm{CHZ}, \mathrm{YXZ}, \mathrm{JD}$, WHW, SJL, YPY, and MM participated in the data collection and interpretation. TJW, DLL, SCT, and HT oversaw the clinical procedure. All authors critically reviewed and approved the final manuscript.

\section{Funding}

No specific funding was received from any bodies in the public, commercial, or not-for-profit sectors to carry out the work described in this article.

\section{Availability of data and materials}

The datasets used and/or analyzed during the current study are available from the corresponding authors on reasonable request.

\section{Ethics approval and consent to participate}

All the procedures reported were in accordance with the ethical standards of the 1975 Helsinki Declaration and its later amendments and were approved by the Ethics Committee of Liaocheng People's Hospital (2020003). Informed consent was obtained from the hWJC-treated COVID-19 patient and the hWJC donor.

\section{Consent for publication}

Consent for publication was obtained from the patient.

\section{Competing interests}

The authors declare that they have no competing interests.

\section{Author details}

${ }^{1}$ Department of Central Laboratory, Liaocheng People's Hospital, Dongchang West Road, No.67, Liaocheng 252000, Shandong Province, China.

2Department of ICU, Liaocheng People's Hospital, Liaocheng 252000, Shandong Province, China. 'Department of CT room, Liaocheng People's Hospital, Liaocheng 252000, Shandong Province, China.

Received: 25 March 2020 Revised: 20 April 2020

Accepted: 11 May 2020 Published online: 27 May 2020

\section{References}

1. Zu ZY, Jiang MD, Xu PP, Chen W, Ni QQ, Lu GM, et al. Coronavirus disease 2019 (COVID-19): a perspective from China. Radiology. 2020;21:200490 https://doi.org/10.1148/radiol.2020200490. PMID: 32083985.

2. Sun P, Lu X, Xu C, Sun W, Pan B. Understanding of COVID-19 based on current evidence. J Med Virol. 2020;25. https://doi.org/10.1002/jmv.25722. PMID: 32096567

3. Liang B, Chen JH, Li T, Wu HY, Yang WJ, Li YJ, et al. Clinical remission of a critically ill COVID-19 patient treated by human umbilical cord mesenchymal stem cells. 2020. chinaXiv:202002.00084. http://chinaxiv.org/ abs/202002.00084

4. Chen N, Zhou M, Dong X, Qu J, Gong F, Han Y, et al. Epidemiological and clinical characteristics of 99 cases of 2019 novel coronavirus pneumonia in Wuhan, China: a descriptive study. Lancet. 2020;395:507-13.
5. Lin L, Lu L, Cao W, Li T. Hypothesis for potential pathogenesis of SARS-CoV2 infection--a review of immune changes in patients with viral pneumonia. Emerg Microbes Infect. 2020;9(1):727-32.

6. Leng ZK, Zhu RJ, Hou W, Feng YM, Yang YL, Han Q, et al. Transplantation of ACE2-mesenchymal stem cells improves the outcome of patients with COVID-19 pneumonia. Aging Dis. 2020;11(2):216-28.

7. Huang C, Wang Y, Li X, Ren L, Zhao J, Hu Y, et al. Clinical features of patients infected with 2019 novel coronavirus in Wuhan, China. Lancet. 2020;395(10223):497-506.

8. Xu Z, Shi L, Wang Y, Zhang J, Huang L, Zhang C, et al. Pathological findings of COVID-19 associated with acute respiratory distress syndrome. Lancet Respir Med. 2020;8(4):420-2.

9. Chen C, Zhang XR, Ju ZY, He WF. Advances in the research of cytokine storm mechanism induced by Corona Virus Disease 2019 and the corresponding immunotherapies. Chin J Burns. 2020;36(0):E005. https://doi.org/10.3760/cma.j. cn501120-20200224-00088. PMID: 32114747. [Epub ahead of print].

10. Le Blanc K, Rasmusson I, Sundberg B, Götherström C, Hassan M, Uzunel M, et al. Treatment of severe acute graft-versus-host disease with third party haploidentical mesenchymal stem cells. Lancet. 2004;363(9419):1439-41.

11. Zhou CH, Yang B, Tian Y, Jiao HL, Zheng WD, Wang J, et al. Immunomodulatory effect of human umbilical cord Wharton's jelly-derived mesenchymal stem cells on lymphocytes. Cell Immunol. 2011:272(1):33-8.

12. Matthay MA, Thompson BT, Read EJ, McKenna DH Jr, Liu KD, Calfee CS, et al. Therapeutic potential of mesenchymal stem cells for severe acute lung injury. Chest. 2010;138(4):965-72.

13. Harrell CR, Sadikot R, Pascual J, Fellabaum C, Jankovic MG, Jovicic N, et al. Mesenchymal stem cell-based therapy of inflammatory lung diseases: current understanding and future perspectives. Stem Cells Int. 2019;2019: 4236973. https://doi.org/10.1155/2019/4236973. PMID: 31191672.

14. New coronavirus pneumonial diagnosis and treatment program (5th ed.) (in Chinese), 2020. http://www.nhc.gov.cn/xcs/zhengcwj/202002/3b09b894 ac9b4204a79db5b8912d4 440.shtml. Accessed 10 Feb 2020.

15. Wang D, Hu B, Hu C, Zhu F, Liu X, Zhang J, et al. Clinical characteristics of 138 hospitalized patients with 2019 novel coronavirus-infected pneumonia in Wuhan, China. JAMA. 2020;323(11):1061-9.

16. Pan F, Ye T, Sun P, Gui S, Liang B, Li L, et al. Time course of lung changes on chest CT during recovery from 2019 novel coronavirus (COVID-19) pneumonia. Radiology. 2020;295(3):715-21.

17. Qin C, Zhou L, Hu Z, Zhang S, Yang S, Tao Y, et al. Dysregulation of immune response in patients with COVID-19 in Wuhan, China. Clin Infect Dis. 2020;12. https://doi.org/10.1093/cid/ciaa248. PMID: 32161940.

18. Sauler M, Bazan IS, Lee PJ. Cell death in the lung: the apoptosis-necroptosis axis. Annu Rev Physiol. 2019;81:375-402.

19. Naji A, Suganuma N, Espagnolle N, Yagyu Kl, Baba N, Sensebé L, et al. Rationale for determining the functional potency of mesenchymal stem cells in preventing regulated cell death for therapeutic use. Stem Cells Transl Med. 2017;6(3):713-9.

\section{Publisher's Note}

Springer Nature remains neutral with regard to jurisdictional claims in published maps and institutional affiliations.

\section{Ready to submit your research? Choose BMC and benefit from:}

- fast, convenient online submission

- thorough peer review by experienced researchers in your field

- rapid publication on acceptance

- support for research data, including large and complex data types

- gold Open Access which fosters wider collaboration and increased citations

- maximum visibility for your research: over $100 \mathrm{M}$ website views per year

At $\mathrm{BMC}$, research is always in progress.

Learn more biomedcentral.com/submissions 